\title{
Adhesive Properties of Silicone-Coated Release Liner Paper Enhanced by Atmospheric Pressure Plasma Pre- and Post-Treatment
}

\author{
Zlata Kelar Tučeková ${ }^{1, *}$,, Oleksandr Galmiz ${ }^{1}$, Jakub Kelar ${ }^{1}$, Dušan Kováčik ${ }^{1}{ }^{\oplus}$, \\ Monika Stupavská ${ }^{1}$, Petra Šrámková ${ }^{1}$, Miroslav Zemánek ${ }^{1}$, Julien Vallade ${ }^{2}$ and Mirko Černák ${ }^{1}$ \\ 1 CEPLANT, Department of Physical Electronics, Faculty of Science, Masaryk University, Kotlářská 2, \\ 61137 Brno, Czech Republic; o.galmiz@mail.muni.cz (O.G.); jakub.kelar@mail.muni.cz (J.K.); \\ dusan.kovacik@mail.muni.cz (D.K.); stupavska@mail.muni.cz (M.S.); petra.sramkova@mail.muni.cz (P.Š.); \\ mzemanek@mail.muni.cz (M.Z.); 54782@mail.muni.cz (M.Č.) \\ 2 Coating Plasma Innovation, $N^{\circ}$ 59, 4ème Rue, ZAC Saint Charles, 13710 Fuveau, France; \\ contact1@cpi-plasma.com \\ * Correspondence: zlata.tucekova@mail.muni.cz; Tel.: +420-770-100-878
}

Received: 12 October 2020; Accepted: 13 November 2020; Published: 17 November 2020

\begin{abstract}
For release-liner preparation, coating stabilization of the silicone layer on base paper often requires pre- and post-treatment. In this study, we used atmospheric pressure diffuse coplanar surface barrier discharge in roll-to-roll configuration. The results of prepared coating showed that the A4 size clay-coated paper sprayed with silicone oil $(0.25-0.50 \mathrm{~mL})$ gradually decreased the tape peeling force $\left(180^{\circ}\right)$ with prolonged and repeated air plasma post-treatment. Best results showing increased hydrophobicity and significantly enhanced release factor of the coating were obtained after the plasma treatment in a nitrogen atmosphere. The silicone coating on the clay-coated paper reduced the reference release force from $5.5 \mathrm{~N} / \mathrm{cm}$ to less than $1.5 \mathrm{~N} / \mathrm{cm}$ after the repeated silicone spraying and short nitrogen plasma post-treatment. The results of X-ray photoelectron spectroscopy and scanning electron microscopy indicate silicone curing by plasma post-treatment and pore-closing of base paper without changes of the bulk material. The aging test lasting 3 months revealed the stability of the prepared coating.
\end{abstract}

Keywords: release liner; clay-coated paper; silicone coating; adhesion; wettability changes; aging; plasma treatment; atmospheric pressure plasma

\section{Introduction}

Release liner papers are used in various self-adhesive applications such as labels, tapes, and medical or hygiene products. The primary function of the release liner is to protect the adhesive layer on the product. It must stick to the adhesive but also be easily removed. The release liner paper is considered as waste after usage. Therefore, the low basis weight papers with efficiently low air permeability are desired $[1,2]$.

Silicones (or polysiloxanes) are currently universally used to produce release liners at the industrial level. Such materials are liquid synthetic polymers with siloxane (-Si-O-) main chains with high thermal and chemical stability. The presence of methyl groups results in a low surface free energy and consequent excellent release properties [3,4].

The crucial requirement of silicone coating is to adhere in the form of a thin layer, especially to low-porosity and smooth paper substrates. The consequent problem of silicone-based release liner papers is transfer and migration from the release coating on the contact surfaces [5]. The high-speed treatment of release liners also decreases the anchorage of silicone $[1,6]$. This effect is not favorable 
because a small proportion of oil detached from the coating can degrade the further adhesion of the product.

The transfer and migration of silicone can be prevented by curing due to crosslinking reaction and creation of a network of chemically bonded polymer chains $[3,7]$. The crosslinking reaction can be achieved using sufficient activation energy and by introducing new functional groups $[3,4]$. The popular curing methods are using a platinum catalyst, thermal curing, and UV curing $[1,7,8]$. The silicones cured by UV radiation and by an electron beam are favorable for coating on thermally sensitive substrates [9]. Some UV curing methods require a nitrogen atmosphere for adequate curing [6,8]. After the condensation of silicone with hydroxyl groups during the storage, self-crosslinking reactions occur at the fiber surface and on functional groups from clay-coated paper. Such post-curing results in a complex polymeric structure and improved chemical stability of coating $[6,10]$.

For the crosslinking reaction of the polymer chain and the formation of radicals and reactive functional groups on different surfaces, we often apply the nonthermal atmospheric pressure plasma sources for various treatment conditions and paper types [11-13]. Diffuse coplanar surface barrier discharge (DCSBD) one such nonthermal plasma source that has found a wide range of applications. The advantages of a concavely curved DCSBD electrode system in a roll-to-roll arrangement are the high speed of the treatment, the precision of material positioning and leading, and the capability of working in different gas atmospheres at atmospheric pressure. Such treatment possibilities are crucial for in-line industrial processing for large-area flexible materials [14-16].

Paper surface pretreatment by nonthermal plasma allows the activation and surface chemistry alteration without a change of bulk properties before the silicone coating. In the next step, the silicone curing or plasma post-treatment of coating provides the necessary agents inevitable for crosslinking of polymer on the surface. In this paper, the effect of DCSBD plasma pretreatment of clay-coated paper for release liner paper production followed by silicone coating and plasma post-treatment was studied. The time and repetition of plasma exposition, as well as the treatment in ambient air and nitrogen, were tested. Analyses of wettability and surface chemistry examined the quality of the treated surface. The aging effect and release factor of the prepared surface were investigated in order to optimize the release properties of the produced release liner paper.

\section{Materials and Methods}

\subsection{Paper}

The details of the tested paper substrate are described in [17]. The one-side "Si-based", single-layer, clay-coated paper, used for release-liner production was provided by Crown Van Gelder company (CVG, Velsen-Noord, The Netherlands) with a base weight and moisture content of $55 \mathrm{~g} / \mathrm{m}^{2}$ and $4.5 \%$, respectively. The experiments were conducted and samples were stored (aged) under the laboratory conditions $\left(23^{\circ} \mathrm{C}, 40-50 \%\right.$ R.H.).

\subsection{Atmospheric Pressure Plasma Treatment}

The description of diffuse coplanar surface barrier discharge (DCSBD) plasma reactor for in-line treatment of flexible substrates is given in the paper by Galmiz et al. [17]. During the experiments of pre/post-treatment, the input power in ambient air and pure nitrogen was $400 \mathrm{~W}$, so that consequent plasma power density was $2.5 \mathrm{~W} \mathrm{~cm}^{-2}$. The distance between the sample and the electrode was kept constant at $0.3 \mathrm{~mm}$ (Figure 1). The treatment speed was $19.2 \mathrm{~m} / \mathrm{min}$, which corresponds to $0.25 \mathrm{~s}$ exposure time. For a set of samples, the substrate was treated repeatedly, resulting in the total plasma exposure time in the range of $0.25-5 \mathrm{~s}$. 


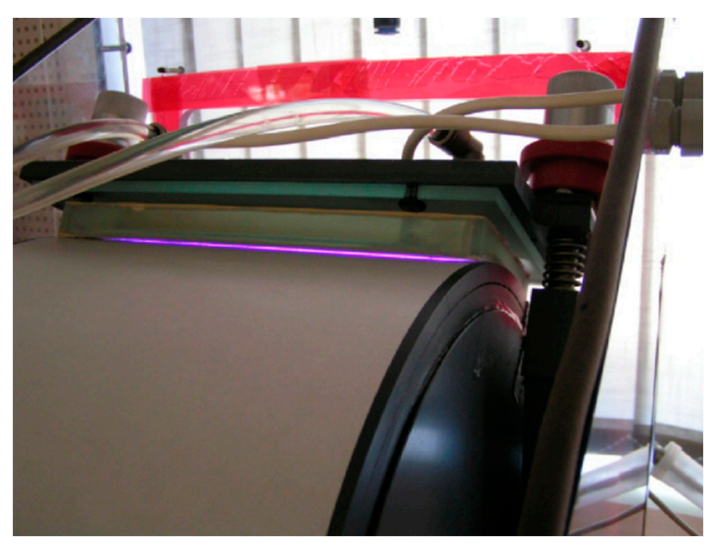

Figure 1. Photo of a closer view of the plasma reactor with a concavely curved diffuse coplanar surface barrier discharge (DCSBD) electrode with the electrode gap of $0.3 \mathrm{~mm}$ [17].

\subsection{Spraying}

To increase the hydrophobicity of prepared release liner paper and decrease the release factor, the A4 samples were coated with silicone oil layer $(0.25-0.50 \mathrm{~mL})$ using a compressed air spray (airbrush) gun. The solvent-free nonreactive silicone oil (polydimethylsiloxane (PDMS); $\left.\left(-\mathrm{Si}\left[\mathrm{CH}_{3}\right]_{2} \mathrm{O}-\right)_{n}\right)$ with the viscosity of $10 \mathrm{cSt}$ was purchased from Sigma Aldrich.

\subsection{Wettability Measurement}

The water contact angle (WCA) and surface free energy (SFE) of the studied paper were analyzed by Surface Energy Evaluation (SEE) system from Advex Instruments (Brno, Czech Republic). The average WCA was evaluated using a minimum of ten droplets with a volume of $1 \mu \mathrm{L}$ for each paper sample.

\subsection{Peel Test}

The peel force, the transfer peel force, and the aging of the coating were measured by the tape peel test at $180^{\circ}$ angle. The AR-1000 Adhesion/Release tester (ChemInstruments, Fairfield, OH, USA) and Tesa 7475 adhesive tape were used in the controlled atmosphere $\left(23{ }^{\circ} \mathrm{C}, \mathrm{RH} 40-50 \%\right)$. The parameters of the peel test were peeling speed $300 \mathrm{~mm} / \mathrm{min}$ and applied force in the range of $0.045-45 \mathrm{~N}$.

\subsection{Scanning Electron Microscopy}

The surface morphology of paper samples was studied by scanning electron microscope MIRA3 from TESCAN (Brno, Czech Republic) using secondary electron emission detectors. The accelerating voltage of primary electrons was $5 \mathrm{kV}$. To avoid surface charging, the samples were coated by $\mathrm{Au} / \mathrm{Pd}$ composite layer $(20 \mathrm{~nm})$.

\subsection{X-ray Photoelectron Spectroscopy}

The XPS measurement was done using ESCALAB 250Xi (Thermo Fisher Scientific, East Grinstead, UK). An X-ray beam with a power of $200 \mathrm{~W}$ and a spot size of $650 \mu \mathrm{m}$ was used. The spectra were collected at $90^{\circ}$ take-off angle and information depth of 3-10 $\mathrm{nm}$. Survey spectra were acquired with a pass energy of $50 \mathrm{eV}$ and an energy step of $1 \mathrm{eV}$. High-resolution scans of Si2p peak were acquired with a pass energy of $20 \mathrm{eV}$ and a step of $0.1 \mathrm{eV}$. An electron flood gun was used to compensate for the charges on the surface. The spectral analyses were done using Avantage software.

\section{Results and Discussion}

Within our research of DCSBD plasma pre/post-treatment, we refer to three different reference samples. The first is the plain Si-based paper as received ("reference"). The second is the Si-based 
paper treated by air plasma only ("plasma-treated"). The third is the Si-based paper coated by silicone oil only ("oil-treated").

As the release liner should be easily removed from the adhesive layer, the measured peel force should be as low as possible. To determine the degree to which impurities stuck to the adhesive layer after the standard peel force test on plasma pre/post-treated oil-coated samples, the transfer peel force was measured. It demonstrated the effect on the peel force during the second usage of the tape but on the reference sample. The goal was to achieve the values as high as the reference sample value, which would indicate the intactness of the adhesive tape and the final product. The reference sample value was the peel force measured by using reference tape on the reference sample. All the measured transfer peel force values were compared to the reference sample value $(5.51 \mathrm{~N} / \mathrm{cm})$.

After long-term storage, the properties of the release liner coating can change. To study this effect, the aging of the coating was evaluated as the ratio of peel force value of the 3-month-stored samples to their initial peel force value, expressed as a percentage.

\subsection{Wettability and Adhesion of Plasma-Treated and Silicone-Coated Paper}

We studied the effect of DCSBD plasma pretreatment and post-treatment time on the WCA in combination with peel force. The stability of the oil coating and its aging are discussed later. While using the silicone oil coating on the paper, one would expect the hydrophobization of the surface. However, the value of WCA of the reference sample $\left(75.0^{\circ}\right)$ increased only slightly after the oil treatment $\left(76.3^{\circ}\right)$. The initial peel force of the reference sample $(5.51 \mathrm{~N} / \mathrm{cm})$ unexpectedly increased for the oil-treated sample $(5.81 \mathrm{~N} / \mathrm{cm})$. This effect could be explained by poor adhesion of the oil to the surface with no active hydroxyl groups $[3,18]$. The other explanation is the migration of the oil to the bulk of the paper, consequently damaging the integrity of the upper clay-coating consisting of hexagonal-shaped kaolinite pigments [9]. The high release force could be then caused by mechanical interlocking of the adhesive due to paper porosity and roughness $[9,19,20]$.

The effect of plasma pretreatment on the WCA and peel force during the silicone coating procedure is shown in Figure 2a. The WCA values decreased with increasing plasma pretreatment time. This indicates the activation of the material and change in its wettability. The oil spraying and the plasma post-treatment resulted in a decrease of peel force value at approx. $3.8 \mathrm{~N} / \mathrm{cm}$. This effect indicates the partial stabilization of silicone oil coating after the post-treatment.
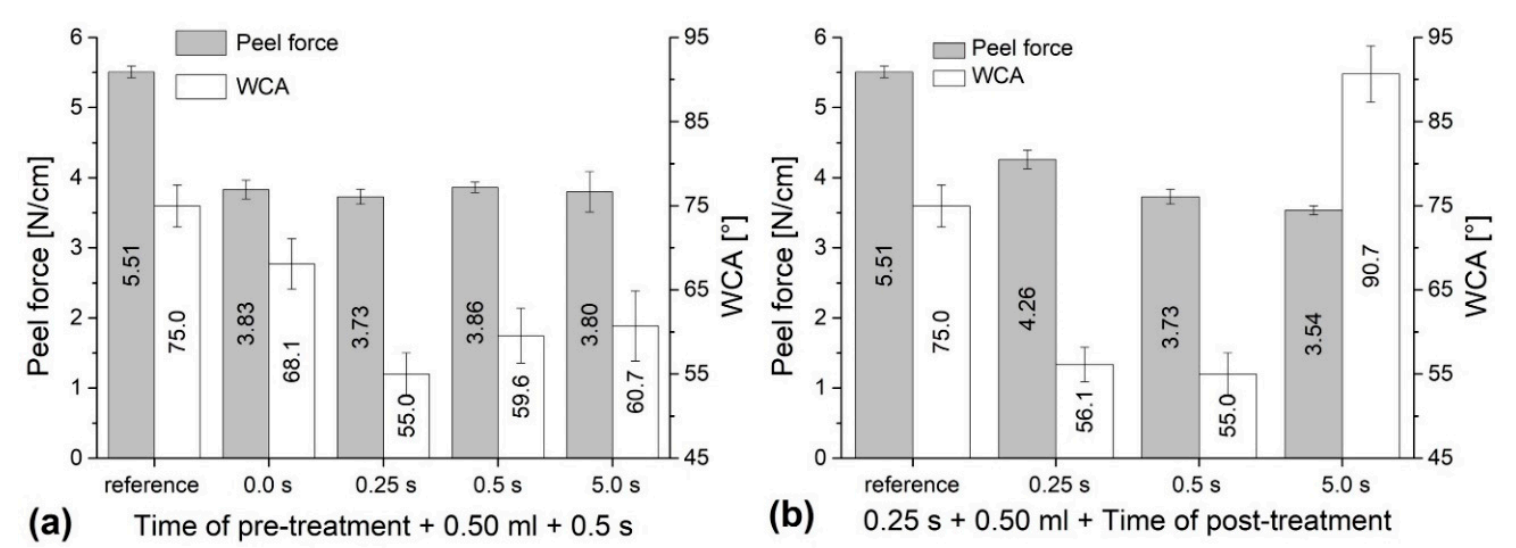

Figure 2. Graphs depicting peel force and water contact angle (WCA) values measured on silicone-coated paper dependent on the air plasma pretreatment (a) and post-treatment $(\mathbf{b})$ time.

Changes in the observed parameters with the increase of post-treatment time are shown in Figure $2 \mathrm{~b}$. The post-treatment after the $0.25 \mathrm{~s}$ pretreatment followed by silicone oil spraying caused the gradual decrease of the peel force to the value of $3.54 \mathrm{~N} / \mathrm{cm}$ after the $5 \mathrm{~s}$ post-treatment time. The short post-treatment decreased the WCA down to $55^{\circ}$, as in the case of pretreatment. Such an 
effect indicates inhomogeneous or insufficient silicone attachment to the surface and thus its migration after the contact with water. However, a remarkable effect was observed after the $5 \mathrm{~s}$ post-treatment. The WCA increased up to $90.7^{\circ}$ and exceeded the reference value that indicates the hydrophobicity of the surface. This result could be explained by the silicone curing process that takes place under the extended exposure to the plasma. The properties of the final coating may be affected by the curing in the presence of organic functional groups and by-products provided by plasma within discharge-gas-coating interaction [21].

One of the requirements for the release liner is the improved release factor of the paper without loss of the adhesive properties of the product. Table 1 summarizes the data of the transfer peel force and percentages of the initial peel force recorded after treatment and after aging. The proportion of oil detached from coating could be estimated by comparison of the transfer peel force to reference value. The release of adhesive tape or final product from the coating should not affect its further adhesion. Practically all the investigated samples showed values of peel force and transfer peel force comparable to the reference peel force values. The prolongation of the plasma exposure time resulted in an increase of transfer peel force percentage. It could be concluded that though some substrate fractions and coating still detached from the release liner to the adhesive tape, this was practically negligible. The storage of the treated samples also had a minor influence on the quality of prepared release liners.

Table 1. The transfer peel force and percentage values of initial peel force right after treatment and after the 3 months of sample aging presented in Figure 2.

\begin{tabular}{cccccc}
\hline Pretreat. (s) & Coating $(\mathbf{m L})$ & Post-Treat. (s) & $\begin{array}{c}\text { Transfer Peel Force } \\
\mathbf{( N / c m )}\end{array}$ & $\begin{array}{c}\text { \% of Initial Transfer } \\
\text { Peel Force }\end{array}$ & $\begin{array}{c}\text { \% of Initial Peel Force } \\
\text { after Aging }\end{array}$ \\
\hline $\mathbf{0}$ & $\mathbf{0 . 5}$ & $\mathbf{0}$ & $5.0 \pm 0.1$ & 91.5 & 96.6 \\
\hline $\mathbf{0}$ & $\mathbf{0 . 5}$ & $\mathbf{0 . 5}$ & $4.9 \pm 0.1$ & 88.5 & 92.8 \\
\hline $\mathbf{0 . 5}$ & $\mathbf{0 . 5}$ & $\mathbf{0 . 5}$ & $4.9 \pm 0.1$ & 89.8 & 94.5 \\
\hline $\mathbf{5}$ & $\mathbf{0 . 5}$ & $\mathbf{0 . 5}$ & torn & 100.0 & 104.4 \\
\hline $\mathbf{0 . 2 5}$ & $\mathbf{0 . 5}$ & $\mathbf{0 . 2 5}$ & $5.1 \pm 0.1$ & 92.8 & 91.5 \\
\hline $\mathbf{0 . 2 5}$ & $\mathbf{0 . 5}$ & $\mathbf{0 . 5}$ & torn & 100.0 & 94.8 \\
\hline $\mathbf{0 . 2 5}$ & $\mathbf{0 . 5}$ & $\mathbf{5}$ & $5.3 \pm 0.1$ & 95.5 & 92.1 \\
\hline
\end{tabular}

One of the possible approaches to enhance the solvent-free silicone by UV radiation within the plasma is the usage of nitrogen as a working (gas) atmosphere $[9,22]$. Because the DCSBD can operate in almost any gas at atmospheric pressure, the sets of samples were differently pretreated and post-treated in the nitrogen atmosphere. The results of the peel force and WCA are shown in Figure 3a.

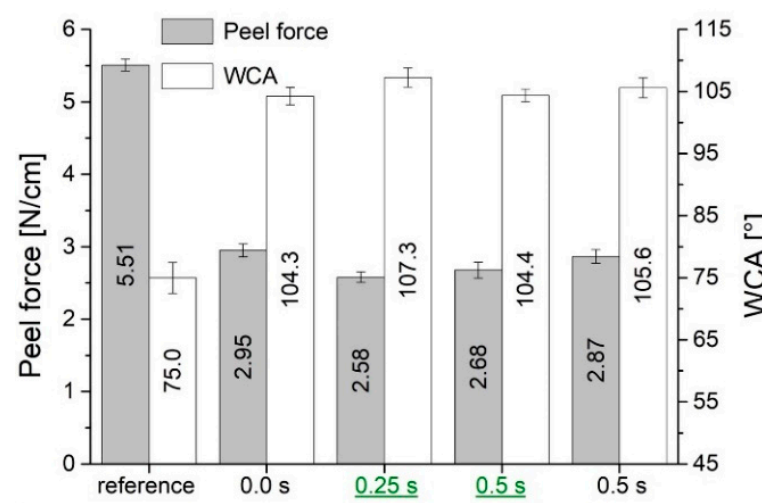

(a)

Time of pre-treatment $+0.50 \mathrm{ml}+\underline{0.5 \mathrm{~s}}$

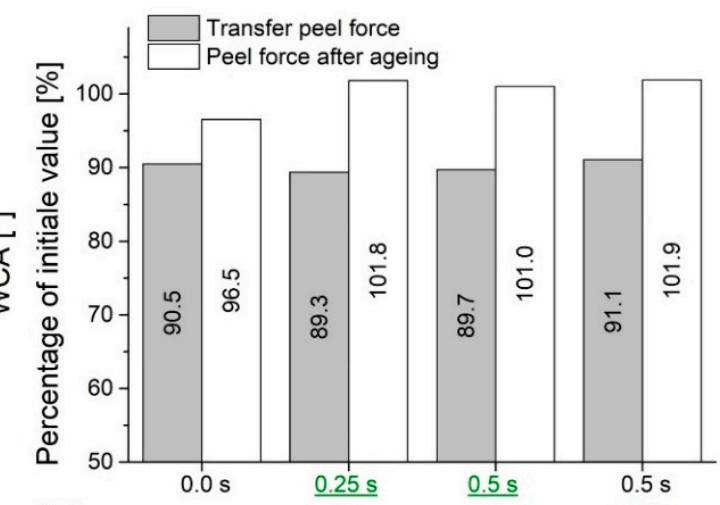

(b) Time of pre-treatment $+0.50 \mathrm{ml}+\underline{0.5 \mathrm{~s}}$

Figure 3. Graphs depicting peel force and WCA values (a) and stability and aging of the coating (b) measured on silicone-coated paper dependent on the pretreatment time with the post-treatment in nitrogen. The treatment in nitrogen is underlined and labeled by green color. 
The obtained data indicate that the short post-treatment in nitrogen is favorable for the release liner properties. The nitrogen plasma post-treatment itself decreased the peel force to values lower than $3 \mathrm{~N} / \mathrm{cm}$. The WCA for all the samples increased to values above $104^{\circ}$. The transfer peel force measured on nitrogen plasma cured surfaces achieved approximately $90 \%$ of the reference value, as shown in Figure $3 b$.

The 3-month-aged surfaces revealed highly stable properties. The peel force after the aging of pretreated and nitrogen post-treated samples increased only to $102 \%$ of its initial value. This means that the desired goals-the stable coating improving release factor and hydrophobicity of surface-were achieved.

To further enhance the effect of coating curing, the plasma treatment time should be increased. The silicone curing can be achieved by repeating the procedure of oil spraying and plasma post-treatment. This procedure was done repeatedly, and these repetitions are referred to as "runs" in the present research. This procedure also ensured the stable temperature of the treated substrate (coating). The number of tested runs was set to a maximum of three. The effect on peel force and WCA was tested for short plasma treatment times in air and nitrogen atmosphere. The results are shown in Figure 4 and Table 2.

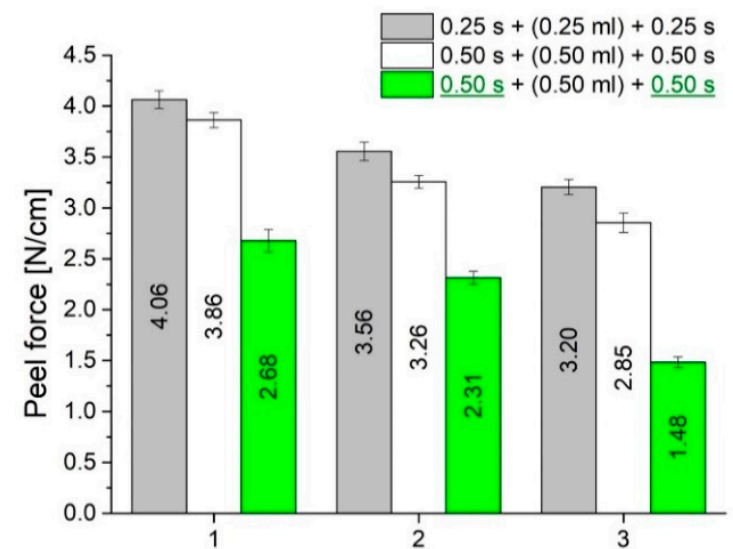

(a)
Number of treatment runs

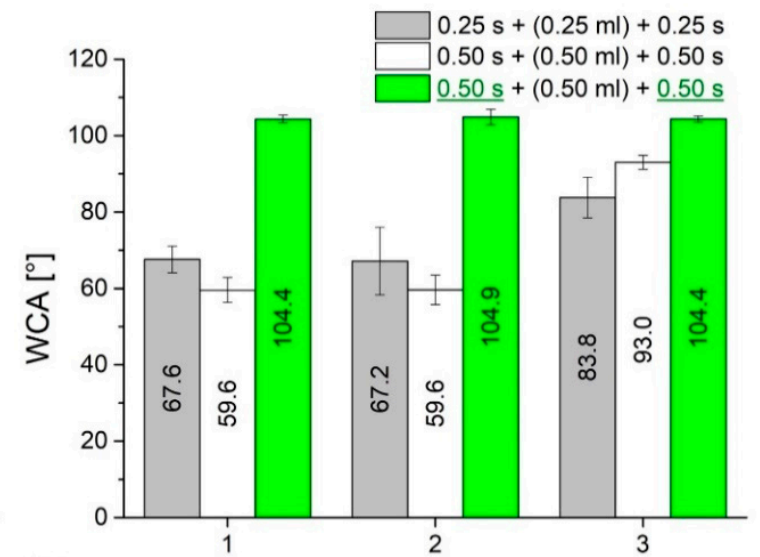

(b)
Number of treatment runs

Figure 4. Graphs depicting peel force (a) and WCA values (b) measured on silicone-coated paper dependent on the number of treatment runs (treatment in nitrogen underlined and labeled green).

Table 2. The transfer peel force and percentage values of initial peel force right after treatment and after the 3 months sample aging presented in Figure 4 (treatment in nitrogen underlined and labeled green).

\begin{tabular}{|c|c|c|c|c|c|c|}
\hline \multicolumn{4}{|c|}{ Sample } & \multirow{2}{*}{$\begin{array}{c}\text { Transfer } \\
\text { Peel Force }(\mathrm{N} / \mathrm{cm})\end{array}$} & \multirow{2}{*}{$\begin{array}{c}\% \text { of Initial } \\
\text { Transfer Peel Force }\end{array}$} & \multirow{2}{*}{$\begin{array}{l}\% \text { of Initial Peel } \\
\text { Force after Aging }\end{array}$} \\
\hline Pretreat. (s) & Coat. (mL) & Post-Treat. (s) & Runs & & & \\
\hline 0.25 & 0.25 & 0.25 & 1 & $4.8 \pm 0.1$ & 87.9 & 97.9 \\
\hline 0.25 & 0.25 & 0.25 & 3 & $4.8 \pm 0.1$ & 87.6 & 101.6 \\
\hline 0.5 & 0.5 & 0.5 & 1 & $4.9 \pm 0.1$ & 89.8 & 94.5 \\
\hline 0.5 & 0.5 & 0.5 & 2 & $4.2 \pm 0.3$ & 75.8 & 91.3 \\
\hline$\overline{0.5}$ & 0.5 & $\overline{0.5}$ & 2 & $5.0 \pm 0.1$ & 90.4 & 97.8 \\
\hline$\overline{0.5}$ & 0.5 & $\overline{0.5}$ & 3 & $4.9 \pm 0.1$ & 88.5 & 126.0 \\
\hline
\end{tabular}

The peel force decreased with the number of runs for all treatment conditions. This effect could be explained by the improvement of the homogeneity of the prepared coating. In Figure 4a, we can observe a slight decrease in peel force with prolonged pre- and post-treatment in air. However, the best results of plasma pre- and post-treatment were achieved using the nitrogen atmosphere (labeled green). The minimal peel force value $(1.5 \mathrm{~N} / \mathrm{cm})$ was achieved in the nitrogen atmosphere after the three runs of oil spraying and plasma post-treatment. 
The decrease of WCA on air-plasma-treated paper was observed after the first two runs. However, after the third run, the WCA increased and achieved a value higher than the reference WCA. The effect of air plasma on the coating could be explained as a curing limit or saturation needed to improve hydrophobic properties and homogeneity of the coating. This is ensured by the gradual addition of oil to the surface and curing by UV, electrons, and functional groups provided by plasma. The WCA significantly increased on nitrogen-plasma-treated paper. However, the increasing number of runs did not alter the resulting value of WCA. The repetition of the silicone spraying and plasma post-treatment process does not seem to enhance the observed effect in the case of a nitrogen atmosphere. We can conclude that the oil on the paper surface was cured after the first run in the nitrogen atmosphere already.

In [23], it was stated that the reason for improved hydrophobicity on nitrogen-plasma-treated PDMS surface was hydrophobic methyl groups exposed by a crosslinked chain and shielding the main chain. The authors believe that the effect of saturation of hydrophobic functional groups occurred. Further crosslinking was achieved after the nitrogen post-treatment. It is known that under the effect of UV radiation, the curing of silicone takes place. During the DCSBD treatment in the nitrogen atmosphere, the radiation in the UV range is more intense than in air [24].

Even though the different authors report the creation of hydrophilic groups of $-\mathrm{NH}_{2}$ on PDMS surface, fast hydrophobic recovery (within $1 \mathrm{~h}$ ) was observed [25]. Further reaction of such functional groups with -OH in plasma and air humidity can affect the crosslinking process [6]. The WCA change toward the hydrophobic properties cannot be directly linked to an improvement of the release factor of oil-coated plasma-treated paper.

The effect of plasma treatment using DCSBD could be compared to air plasma pre- and post-treatment of silicone-coated paper using volume dielectric barrier discharge ("industrial corona") published in Štěpánová et al. [11]. The reported peel force and corresponding WCA values of $0.25 \mathrm{~s}$ pretreated paper after the runs of $0.25 \mathrm{~mL}$ oil coating and $0.25 \mathrm{~s}$ post-treatment were $4.3 \mathrm{~N} / \mathrm{cm}$ and $63.5^{\circ}$ after the first, $3.9 \mathrm{~N} / \mathrm{cm}$ and $68.4^{\circ}$ after the second, and $3.5 \mathrm{~N} / \mathrm{cm}$ and $80.5^{\circ}$ after the third run. The results of peel force for short atmospheric pressure plasma exposition are in favor of DCSBD plasma treatment, while the WCA values after industrial corona treatment are similar within its errors $\left( \pm 3-5^{\circ}\right)$.

In [11], the reported minimal peel force and corresponding WCA values on industrial-coronatreated paper $(0.5 \mathrm{~s}+0.5 \mathrm{~mL}+0.5 \mathrm{~s})$ were $2.9 \mathrm{~N} / \mathrm{cm}$ and $79.2^{\circ}$ after the first, $2.6 \mathrm{~N} / \mathrm{cm}$ and $91.3^{\circ}$ after the second, and $2.1 \mathrm{~N} / \mathrm{cm}$ and $88.4^{\circ}$ after the third run. These values indicate the enhancement of silicone coating by optimized industrial corona treatment. Such improvement of the release factor could also be explained by additional thermal silicone curing [26] within the filaments of industrial corona discharge $[16,27,28]$. However, more extended industrial corona treatment causes higher WCA deviation often linked to a nonhomogeneous treatment of the surface [29-31].

\subsection{Morphology of the Plasma-Treated and Silicone-Coated Surface}

The morphology of samples observed by SEM is shown in Figure 5 . The $0.5 \mathrm{~s}$ pretreated paper with $0.5 \mathrm{~mL}$ oil coating $(\mathrm{b})$ shows the decreased porosity of the surface. However, the sample post-treated for $0.5 \mathrm{~s}$ (c) shows a morphology similar to those of the samples treated by the DCSBD plasma published in [17].

The air DCSBD plasma post-treated samples show a decrease in the porosity of the silicone-coated paper in comparison to the reference sample. The creation of larger areas with visually smoothened texture is then more visible with the increased pre- and post-treatment time $(\mathrm{d}, \mathrm{e})$. A similar effect was observed on the nitrogen DCSBD plasma pre/post-treated sample (f). This effect can be related to the siliconization of coating observed on cellulose paper in [6].

It is seen in the SEM micrograph (d) that even maximum pretreatment time does not affect the surface of the treated sample. After the usage of the silicon oil and following plasma-curing, the roughness of the surface was not changed. However, the pores in the material were no longer present. The authors suggest that the silicone film covered the surface. 

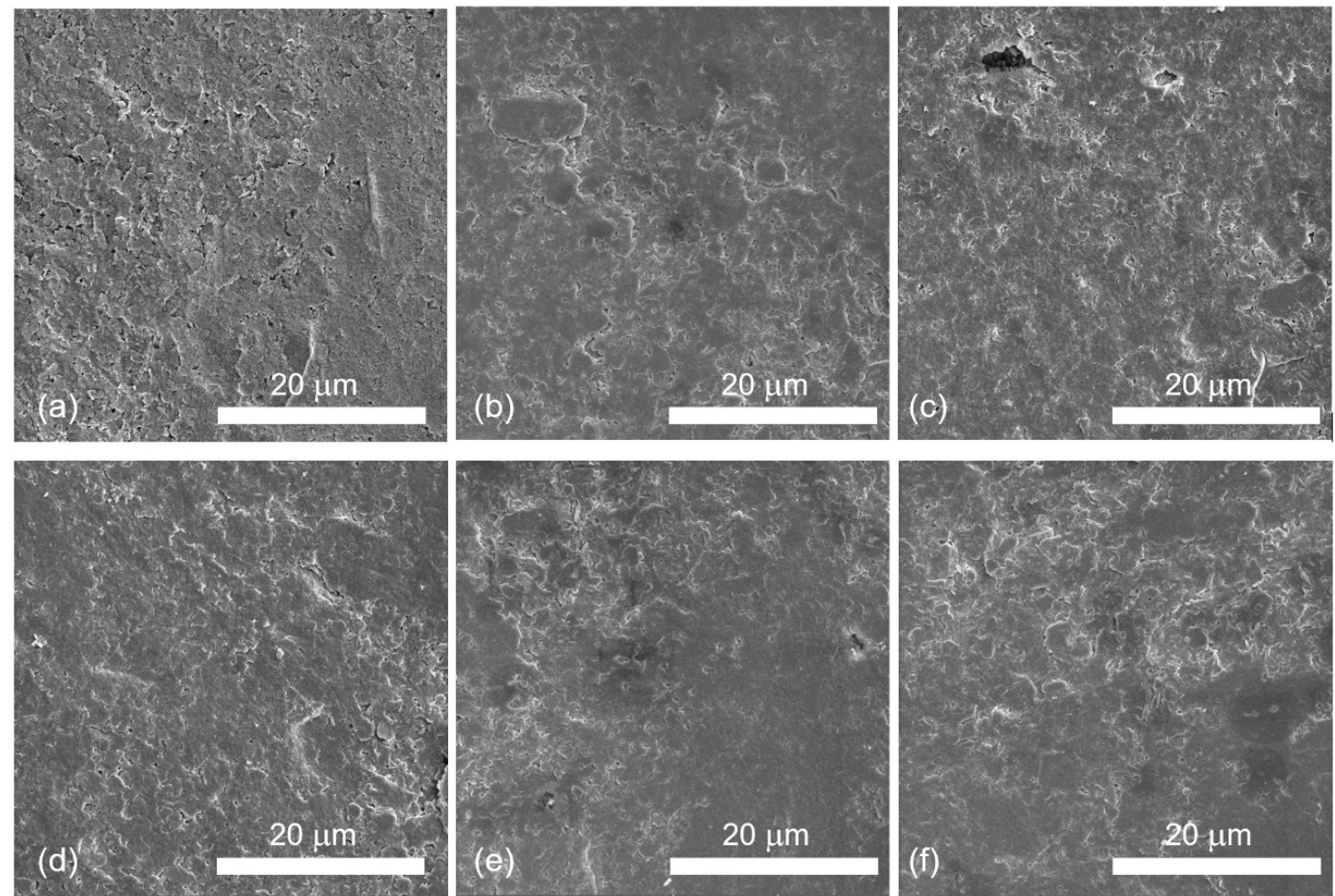

Figure 5. SEM micrographs of untreated (a) and $0.5 \mathrm{~mL}$ silicone-coated paper plasma pre/post-treated in air for $0.5 / 0 \mathrm{~s} \mathrm{(b),} \mathrm{0.5/0.5} \mathrm{s} \mathrm{(c),} \mathrm{0.5/5} \mathrm{s} \mathrm{(d),} \mathrm{and} \mathrm{5/5} \mathrm{s} \mathrm{(e)} \mathrm{and} \mathrm{in} \mathrm{nitrogen} \mathrm{for} \mathrm{0.5/0.5} \mathrm{s} \mathrm{(f)} \mathrm{(scale:} 20 \mu \mathrm{m})$.

\subsection{Chemical Composition of the Plasma-Treated and Silicone-Coated Surface}

The chemical composition on the treated paper surface is shown in Table 3. Table 3 lists the relevant element concentrations, and the $\mathrm{Na}, \mathrm{N}, \mathrm{Ca}$, and $\mathrm{Cl}$ concentrations are excluded, as these varied within the range of $0-2 \%$. The elemental composition of the reference sample originates from the clay $\left(\mathrm{Al}_{2} \mathrm{O}_{3} \cdot 2 \mathrm{SiO}_{2} \cdot 2 \mathrm{H}_{2} \mathrm{O}\right)$-coating and from seizing by alkenyl succinic anhydride (ASA) covering the base [17].

Table 3. Chemical composition of paper samples measured by XPS (treatment in nitrogen underlined and labeled green).

\begin{tabular}{ccccccccc}
\hline & Sample & \multicolumn{7}{c}{ XPS (Atomic \%) } \\
\hline Pretreat. (s) & Coating $(\mathbf{m L})$ & Post-Treat. (s) & $\mathbf{O}$ & $\mathbf{C}$ & $\mathbf{S i}$ & $\mathbf{A l}$ & $\mathbf{O} / \mathbf{C}$ & Si/C \\
\hline $\mathbf{0}$ & $\mathbf{0}$ & $\mathbf{0}$ & 34 & 47 & 9 & 8 & 0.7 & 0.2 \\
\hline $\mathbf{0 . 5}$ & $\mathbf{0}$ & $\mathbf{0}$ & 40 & 41 & 9 & 7 & 1.0 & 0.2 \\
\hline $\mathbf{0}$ & $\mathbf{0 . 5}$ & $\mathbf{0}$ & 40 & 40 & 10 & 8 & 1.0 & 0.3 \\
\hline $\mathbf{0 . 5}$ & $\mathbf{0 . 5}$ & $\mathbf{0}$ & 40 & 40 & 13 & 7 & 1.0 & 0.3 \\
\hline $\mathbf{5}$ & $\mathbf{0 . 5}$ & $\mathbf{0}$ & 41 & 37 & 14 & 7 & 1.1 & 0.4 \\
\hline $\mathbf{0 . 5}$ & $\mathbf{0 . 5}$ & $\mathbf{0 . 5}$ & 42 & 37 & 14 & 7 & 1.2 & 0.4 \\
\hline $\mathbf{0 . 5}$ & $\mathbf{0 . 5}$ & $\mathbf{5}$ & 42 & 31 & 24 & 2 & 1.4 & 0.8 \\
\hline $\mathbf{5}$ & $\mathbf{0 . 5}$ & $\mathbf{0 . 5}$ & 42 & 34 & 16 & 7 & 1.2 & 0.5 \\
\hline $\mathbf{5}$ & $\mathbf{0 . 5}$ & $\mathbf{5}$ & 37 & 38 & 25 & 0 & 1.0 & 0.6 \\
\hline $\mathbf{0 . 5}$ & $\mathbf{0 . 5}$ & $\mathbf{0 . 5}$ & 38 & 38 & 20 & 4 & 1.0 & 0.5 \\
\hline $\mathbf{0 . 5}$ & $\mathbf{0 . 5}$ & $\mathbf{0 . 5}$ & 36 & 39 & 22 & 4 & 0.9 & 0.6 \\
\hline
\end{tabular}

In the plasma-treated paper, we observed a significant change in $\mathrm{O}$ and $\mathrm{C}$ atomic percent concentrations. Thus, the $\mathrm{O} / \mathrm{C}$ ratio increased in comparison to the reference sample. In the oil-treated paper, the $\mathrm{Si} / \mathrm{C}$ ratio slightly increased as expected after the silicone oil spraying, though a much higher increase of the Si concentration was expected. One of the possible explanations of such a slight 
effect could be the migration of the silicone oil into the bulk of the non-plasma-treated paper and its evaporation while pumping the XPS chamber.

Within samples discussed later, the authors refer to "Si incorporation" as the Si atomic percent increase of the specific sample in comparison to the reference value (9\%). The results show that the short $(0.5 \mathrm{~s})$ DCSBD plasma pretreatment in air followed by oil spraying improved the $\mathrm{Si} / \mathrm{C}$ ratio in comparison to the reference sample. The Si incorporation on the surface was higher $(+4 \%)$ in comparison to the oil-treated sample. It is suggested that plasma pretreatment of the paper prevents $\mathrm{Si}$ migration of the silicone oil into the bulk of the paper and its evaporation while pumping the XPS chamber $[3,9,20]$. This effect took place on all the pretreated samples. Prolonged plasma pretreatment caused a further increase in the Si concentration.

In comparison to the pretreatment time effect, post-treatment in the ambient air affected both 0.5 and $5 \mathrm{~s}$ pretreated samples. The prolonged plasma post-treatment had a more significant impact on the Si concentration. After the $5 \mathrm{~s}$ post-treatment, the Si incorporation increased more significantly for both pretreated samples $(+15-16 \%)$ in comparison to samples without post-treatment $(+4-5 \%)$. This effect was accompanied by the increase of the $\mathrm{O} / \mathrm{C}$ ratio. This considerable increase indicates an effect of plasma-induced curing and silicone stabilization by crosslinking and creating the chemical bonds within the polymer chain and functional groups on the coated surface [3]. The structure of dimethylsiloxane prevents the formation of unsaturated bonds in segments of $\left(-\mathrm{Si}_{(}\left(\mathrm{CH}_{3}\right)_{2} \mathrm{O}-\right)_{n}$. Thus, the processes expected in the main chain are the direct crosslinking (combination of radicals) or oxidation of radicals, presumably again followed by crosslinking [32,33]. These processes could also be enhanced by prolonged post-treatment in air. Further, the Al concentration originating from the clay composition decreased significantly after the $5 \mathrm{~s}$ post-treatment.

The short air plasma pretreatment followed by short plasma post-treatment in nitrogen led to a significant increase in the Si concentration. A similar effect was observed for the short nitrogen plasma pre- and post-treatment. Nitrogen plasma treatment increased the Si incorporation $(+11-13 \%)$ in comparison with air plasma $(+5 \%)$. The decrease of $\mathrm{O}$ and $\mathrm{C}$ concentration was observed after the nitrogen plasma interaction with polymer chain and functional groups on the surface.

The XPS spectra of Si2p peak for untreated PDMS often show the dominancy of the siloxane $\left(\mathrm{SiO}_{2} \mathrm{C}_{2}\right)$ group or silicone. After the treatment by hyperthermal hydrogen or oxygen/nitrogen plasma, the polymer chains are crosslinked mostly through the formation of radicals from methyl groups and subsequent reactions [32,34]. The siloxane part is converted and the spectra are shifted towards the silicate $[23,35-38]$. These authors also observed the formation of a silica-like structure on the PDMS surface.

The XPS spectra of Si2p peak (data not shown) of untreated clay-coated paper overlaid the silicate bands. After the DCSBD plasma treatment and silicone coating, the spectra shifted towards the silicone groups (Figure 6). The shift was more pronounced with the time of the post-treatment $(a-b)$. The sample pre- and post-treated for $5 \mathrm{~s}$ in air (c) shifted to the position similar to the untreated PDMS substrates [35,36]. This effect and diminished concentration of Al suggest the creation of the cured silicone layer covering the clay-coated paper. Furthermore, the changes towards a PDMS-like coating improved the hydrophobic properties of the surface.

The sample briefly post-treated in the nitrogen DCSBD plasma (Figure 6d) showed a tendency similar to that of the $5 \mathrm{~s}$ pre/post-treated sample. Furthermore, the XPS analyses of these samples showed a slight increase of silicate bonds within Si2p, and a visible increase of highly oxidized bonds within C1s spectra was also observed in [23]. This was achieved by prolonged air plasma pre/post-treatment and by autoxidation during aging on the nitrogen-plasma-treated sample. Such a process often affects the materials treated by nitrogen DCSBD plasma $[17,28,39]$. 

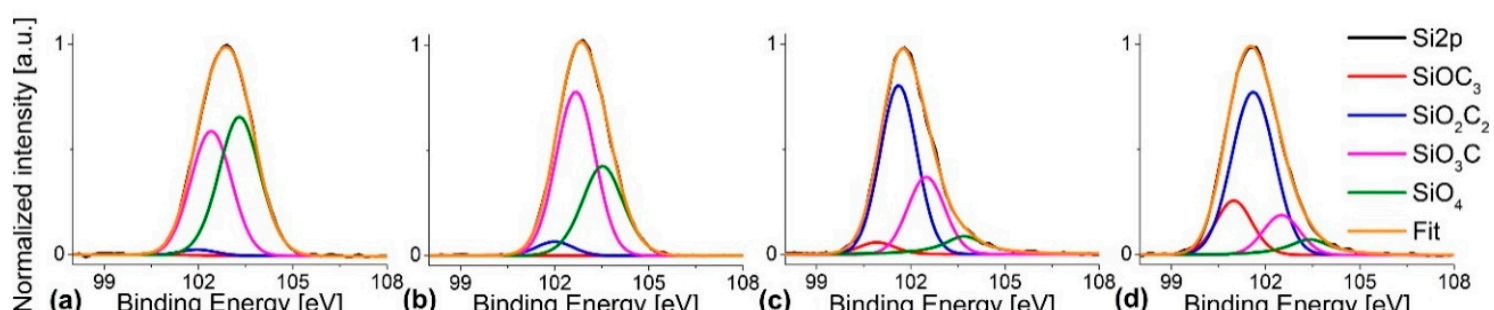

(a) ${ }^{99}$ Binding Energy $[\mathrm{eV}]$

Figure 6. The high-resolution spectra of Si2p peak for $0.5 \mathrm{~mL}$ silicone-coated paper plasma pre/post-treated in air for $0.5 / 0.5 \mathrm{~s} \mathrm{(a),} 0.5 / 5 \mathrm{~s} \mathrm{(b)}$, and $5 / 5 \mathrm{~s} \mathrm{(c)} \mathrm{and} \mathrm{pretreated} 0.5 \mathrm{~s}$ in air and post-treated $0.5 \mathrm{~s}$ in nitrogen $(\mathbf{d})$.

\section{Conclusions}

The DCSBD plasma pre- and post-treatment was tested for the preparation of a stable silicone coating on release liner paper. The release factor of the coating was improved with the increase in air plasma post-treatment time. The decrease of peel force $(2.9 \mathrm{~N} / \mathrm{cm})$ needed to remove testing adhesive tape was achieved with the repetition of silicone oil spraying and post-treatment procedure. The change of contact angle towards hydrophobicity $\left(>90^{\circ}\right)$ of the surface was achieved after the $5 \mathrm{~s}$ plasma post-treatment. The 3 months of aging of prepared release liners showed no or slight degradation of coating and its release factor.

The nitrogen plasma pre/post-treatment gradually enhanced the release factor and hydrophobic properties $\left(>104^{\circ}\right)$ of prepared silicone coating. The best peel force result $(1.5 \mathrm{~N} / \mathrm{cm})$ was achieved after the third repetition of oil spraying and short plasma post-treatment $(0.5 \mathrm{~s})$ in the nitrogen atmosphere. The improvement suggests the effect of saturation of hydrophobic functional groups and silicone curing after the repeated nitrogen plasma post-treatment.

The SEM micrographs showed the creation of large smoothened areas on the clay-coated paper after the treatment. The surface porosity decreased, and compact layers were more visible with prolonged air plasma pretreatment time and treatment in the nitrogen plasma.

The chemical composition of the treated samples was also changed. The pronounced $\mathrm{Si}$ incorporation and $\mathrm{Si} / \mathrm{C}$ ratio increase were achieved after the post-treatment for $5 \mathrm{~s}$ in air plasma and $0.5 \mathrm{~s}$ in nitrogen plasma. The XPS results suggest the crosslinking of the PDMS chains and the consequent formation of a partly crosslinked silicone polymer layer.

The best results, such as low release factor, hydrophobic properties, significant $\mathrm{Si}$ incorporation, and compact homogeneous layer preparation, were achieved in the nitrogen atmosphere. Thus, the DCSBD nitrogen plasma represents an efficient silicone curing technology for release liner preparation. The high treatment speed and capability of working in an in-line regime correspond with the industrial requirements of release liner production.

Author Contributions: Conceptualization, Z.K.T. and O.G.; methodology, D.K., M.Z., and J.V.; data curation, Z.K.T., O.G., J.K., M.S., D.K., and J.V.; writing—original draft preparation, Z.K.T., O.G., and P.Š.; writing-review and editing, Z.K.T., O.G., and J.K.; visualization, Z.K.T. and J.K.; supervision, D.K., M.Z., and M.Č.; project administration, D.K. and J.V.; funding acquisition, J.V. and M.Č. All authors have read and agreed to the published version of the manuscript.

Funding: This research was supported by the project 7D16003 funded by EUROSTARS 2 and projects LM2018097 funded by Ministry of Education Youth and Sports of the Czech Republic. This work was also supported by Project "Postdoc@MUNI" (no. CZ.02.2.69/0.0/0.0/16_027/0008360), founded by Operational Programme Research, Development and Education.

Acknowledgments: The authors would like to thank Crown Van Gelder B.V. (CVG), The Netherlands, for the "Si-base" paper samples and Coating Plasma Innovation (CPI), France, for collaboration on the above-mentioned EUROSTARS 2 project and peel force measurements. The authors would also like to acknowledge the help of Jan Čech from Masaryk University.

Conflicts of Interest: The authors declare no conflict of interest. 


\section{References}

1. Isoaho, T. Value Chain Analysis of Specialty Papers; Aalto University: Espoo, Finland, 2019.

2. Bilodeau, M.A.; Hamilton, R.H. Release Paper and Method of Manufacture. U.S. Patent US20150125658A1, 7 May 2015.

3. Belosinschi, D.; Chabot, B.; Brouillette, F. Release paper: Can phosphate esters be an alternative to silicone? BioResources 2012, 7, 902-912.

4. Colas, A.; Cray, S. Silicones in Industrial Applications. In Inorganic Polymers; Gleria, M., De Jaeger, R., Eds.; Nova Science Publishers: New York, NY, USA, 2007; pp. 61-161.

5. Vangeneugden, D.; Dubreuil, M.; Bongaers, E.; Hendrix, W. Atmospheric DBD plasma deposition of ECO-friedly release liners for pressure sensitive adhesive tapes. Contrib. Plasma Phys. 2009, 49, 648-654. [CrossRef]

6. von Gradowski, S.; Torborg, C.; Biesalski, M. Preparation and characterization of cellulose-based barrier coatings for producing a release-liner out of a porous base paper. Cellulose 2019, 26, 1881-1894. [CrossRef]

7. Holwell, A.J. Optimised Technologies Are Emerging Which Reduce Platinum Usage in Silicone Curing. Platin. Met. Rev. 2008, 52, 243-246. [CrossRef]

8. Cray, S. Silicone release coatings for the pressure sensitive adhesive industry. In Silicones in Industrial Applications; Andriot, M., DeGroot, J.V., Meeks, R., Eds.; Nova Science Publisher: New York, NY, USA, 2009; pp. 38-43.

9. Von Gradowski, S. Dissertation: Biogenic Polymers: From Barrier Coatings towards the Design of Novel Low-Adhesive Release Liner; Technical University: Darmstadt, Germany, 2019.

10. Eduok, U.; Faye, O.; Szpunar, J. Recent developments and applications of protective silicone coatings: A review of PDMS functional materials. Prog. Org. Coat. 2017, 111, 124-163. [CrossRef]

11. Štěpánová, V.; Kováčik, D.; Galmiz, O.; Tučeková, Z.; Zemánek, M.; Stupavská, M.; Kelar, J.; Vallade, J.; Černák, M. Industrial corona pre- and post-treatment for enhanced silicone coating of paper used as release liner. In Proceedings of the NANOCON 2017-Conference Proceedings, 9th International Conference on Nanomaterials-Research and Application, Brno, Czech Republic, 18-20 October 2017; pp. 271-276.

12. Pykönen, M. Influence Plasma Modification on Surface Properties and Offset Printability; Åbo Akademi University: Turku, Finland, 2010.

13. Garcia-Torres, J.; Sylla, D.; Molina, L.; Crespo, E.; Mota, J.; Bautista, L. Surface modification of cellulosic substrates via atmospheric pressure plasma polymerization of acrylic acid: Structure and properties. Appl. Surf. Sci. 2014, 305, 292-300. [CrossRef]

14. Krumpolec, R.; Zemánek, M.; Tučeková, Z.; Kelar, J. Roll-to-roll surface etching of polymers using hydrogen plasma at atmospheric pressure. In Proceedings of the NANOCON 2017-Conference Proceedings, 9th International Conference on Nanomaterials-Research and Application, Brno, Czech Republic, 18-20 October 2017; pp. 283-288.

15. Doubková, Z.; Tučeková, Z.; Kelar, J.; Krumpolec, R.; Zemánek, M. Modification of Various Polymer Surfaces Using Atmospheric Pressure Reducing Plasma. In Proceedings of the NANOCON2018 Conference Proceedings-10th Anniversary International Conference on Nanomaterials-Research and Application, Brno, Czech Republic, 17-19 October 2018; pp. 688-693.

16. Černák, M.; Kováčik, D.; Ráhel', J.; St’ahel, P.; Zahoranová, A.; Kubincová, J.; Tóth, A.; Černáková, L. Generation of a high-density highly non-equilibrium air plasma for high-speed large-area flat surface processing. Plasma Phys. Control. Fusion 2011, 53, 124031. [CrossRef]

17. Galmiz, O.; Tucekova, Z.K.; Kelar, J.; Zemanek, M.; Stupavska, M.; Kovacik, D.; Cernak, M. Effect of atmospheric pressure plasma on surface modification of paper. AIP Adv. 2019, 9, 105013. [CrossRef]

18. Arkles, B. Tailoring Surfaces with Silanes. Chem. Tech. 1977, 7, 766-778.

19. Pocius, A.V. Adhesion and Adhesives Technology an Introduction, 3rd ed.; Carl Hanser Verlag: Munich, Germany, 2012.

20. Sun, S.; Li, M.; Liu, A. A review on mechanical properties of pressure sensitive adhesives. Int. J. Adhes. Adhes. 2013, 41, 98-106. [CrossRef] 
21. Panou, A.I.; Papadokostaki, K.G.; Tarantili, P.A.; Sanopoulou, M. Effect of hydrophilic inclusions on PDMS crosslinking reaction and its interrelation with mechanical and water sorption properties of cured films. Eur. Polym. J. 2013, 49, 1803-1810. [CrossRef]

22. Vert, P.T.; Cray, S. Pressure sensitive tape council. In Proceedings of the TECH 30: Global Conference VI, Hyatt Regency Grand Cypress, Orlando, FL, USA, 16-18 May 2007; PSTC, Northbrook, Ill: Orlando, FL, USA, 2007; p. 302.

23. Gomathi, N.; Mishra, I.; Varma, S.; Neogi, S. Surface modification of poly(dimethylsiloxane) through oxygen and nitrogen plasma treatment to improve its characteristics towards biomedical applications. Surf. Topogr. Metrol. Prop. 2015, 3, 35005. [CrossRef]

24. Mošovská, S.; Medvecká, V.; Gregová, M.; Tomeková, J.; Valík, L’.; Mikulajová, A.; Zahoranová, A. Plasma inactivation of Aspergillus flavus on hazelnut surface in a diffuse barrier discharge using different working gases. Food Control 2019, 104, 256-261. [CrossRef]

25. Yang, C.; Yuan, Y.J. Investigation on the mechanism of nitrogen plasma modified PDMS bonding with SU-8. Appl. Surf. Sci. 2016, 364, 815-821. [CrossRef]

26. Si, Z.; Li, J.; Ma, L.; Cai, D.; Li, S.; Baeyens, J.; Degrève, J.; Nie, J.; Tan, T.; Qin, P. The Ultrafast and Continuous Fabrication of a Polydimethylsiloxane Membrane by Ultraviolet-Induced Polymerization. Angew. Chem. Int. Ed. 2019, 58, 17175-17179. [CrossRef]

27. Černák, M.; Černáková, L.; Hudec, I.; Kováčik, D.; Zahoranová, A. Diffuse Coplanar Surface Barrier Discharge and its applications for in-line processing of low-added-value materials. Eur. Phys. J. Appl. Phys. 2009, 47, 22806. [CrossRef]

28. Kormunda, M.; Homola, T.; Matousek, J.; Kovacik, D.; Cernak, M.; Pavlik, J. Surface analysis of poly(ethylene naphthalate) (PEN) films treated at atmospheric pressure using diffuse coplanar surface barrier discharge in air and in nitrogen. Polym. Degrad. Stab. 2012, 97, 547-553. [CrossRef]

29. Hanusová, J.; Kováčik, D.; Stupavská, M.; Černák, M.; Novák, I. Atmospheric pressure plasma treatment of polyamide-12 foils. Open Chem. 2015, 13, 382-388. [CrossRef]

30. Kováčik, D.; Maxa, J.; Skácelová, D.; Kršková, J.; Stupavska, M.; Zahoranová, A.; Černák, M. Low-cost and in-line plasma treatment of BOPP films. In Proceedings of the Sborník konference Plastko, Brno, Czech Republic, 20-21 April 2016; p. 12.

31. Kovacik, D.; Skacelova, D.; Krskova, J.; Cernak, M. Modification of Polymer Surfaces by Atmospheric Pressure Plasmas. In Proceedings of the Hakone XV: International Symposium on High Pressure Low Temperature Plasma Chemistry: With Joint Cost Td1208 Workshop: Non-Equilibrium Plasmas with Liquids for Water and Surface Treatment, Brno, Czech Republic, 11-16 September 2016; Cernak, M., Hoder, T., Eds.; Masaryk University Press: Brno, Czech Republic, 2016; pp. 262-265.

32. Kornacka, E.; Kozakiewicz, J.; Legocka, I.; Przybylski, J.; Przybytniak, G.; Sadło, J. Radical processes induced in poly(siloxaneurethaneureas) by ionising radiation. Polym. Degrad. Stab. 2006, 91, 2182-2188. [CrossRef]

33. Cleland, M.R.; Parks, L.A.; Cheng, S. Applications for radiation processing of materials. In Ionizing Radiation and Polymers; Wertheimer, M.R., Ed.; Elsevier: Amsterdam, The Netherlands, 2003; pp. 66-74.

34. Miller, A.A. Radiation Chemistry of Polydimethylsiloxane. I. Crosslinking and Gas Yields. J. Am. Chem. Soc. 1960, 82, 3519-3523. [CrossRef]

35. Hillborg, H.; Ankner, J.F.; Gedde, U.W.; Smith, G.D.; Yasuda, H.K.; Wikström, K. Crosslinked polydimethylsiloxane exposed to oxygen plasma studied by neutron reflectometry and other surface specific techniques. Polymer (Guildf) 2000, 41, 6851-6863. [CrossRef]

36. Lee, D.; Yang, S. Surface modification of PDMS by atmospheric-pressure plasma-enhanced chemical vapor deposition and analysis of long-lasting surface hydrophilicity. Sens. Actuators B Chem. 2012, 162, 425-434. [CrossRef]

37. Chen, J.T.; Fu, Y.J.; Tung, K.L.; Huang, S.H.; Hung, W.S.; Jessie Lue, S.; Hu, C.C.; Lee, K.R.; Lai, J.Y. Surface modification of poly(dimethylsiloxane) by atmospheric pressure high temperature plasma torch to prepare high-performance gas separation membranes. J. Memb. Sci. 2013, 440, 1-8. [CrossRef] 
38. Bao, C.; Xu, K.Q.; Tang, C.Y.; Lau, W.M.; Yin, C.B.; Zhu, Y.; Mei, J.; Lee, J.; Hui, D.; Nie, H.Y.; et al. Cross-linking the surface of cured polydimethylsiloxane via hyperthermal hydrogen projectile bombardment. ACS Appl. Mater. Interfaces 2015, 7, 8515-8524. [CrossRef]

39. Novák, I.; Popelka, A.; Sedliacik, J.; Chodák, I.; Vanko, V.; Tóth, A.; JURKOVIČ, P.; PRACHÁR, J.; Sivova, M. Modification of the polyamide foil by Diffuse Coplanar Barrier Discharge plasma for furniture applications. For. Wood Technol. 2013, 83, 292-296.

Publisher's Note: MDPI stays neutral with regard to jurisdictional claims in published maps and institutional affiliations.

(C) 2020 by the authors. Licensee MDPI, Basel, Switzerland. This article is an open access article distributed under the terms and conditions of the Creative Commons Attribution (CC BY) license (http://creativecommons.org/licenses/by/4.0/). 